Please do not remove this page

RMIT

UNIVERSITY

\title{
Use of Markov chain for deterioration modelling and risk management of infrastructure assets
}

Sharabah, Abdulkader; Setunge, Sujeeva; Zeephongsekul, Panlop

https://researchrepository.rmit.edu.au/esploro/outputs/9921862327201341/filesAndLinks?institution=61RMIT_INST\&index=null

Sharabah, A., Setunge, S., \& Zeephongsekul, P. (2006). Use of Markov chain for deterioration modelling and risk management of infrastructure assets. Proceedings of the International Conference on Information and Automation, 384-389. https://doi.org/10.1109/ICINFA.2006.374109

Published Version: https://doi.org/10.1109/ICINFA.2006.374109

Repository homepage: https://researchrepository.rmit.edu.au

(C) 2006 IEEE

Downloaded On 2023/04/26 21:40:34 +1000

Please do not remove this page 


\title{
Use of Markov Chain for Deterioration Modeling and Risk Management of Infrastructure Assets
}

\author{
Abdulkader Sharabah, Sujeeva Setunge and Panlop Zeephongsekul \\ *School of Civil and Chemical Engineering \\ RMIT University, GPO Box 2476V, Melbourne, Australia, 3001 \\ Telephone: 6139925 2182, Fax: 61396390138 \\ Email: SUJEEVA.SETUNGE@RMT.EDU.AU
}

\begin{abstract}
Current annual expenditure for management and renewal of infrastructure assets around the world is 500 billion US dollars. With an aging stock of infrastructure, innovative methods for management of risk of failure and optimizing of maintenance expenditure becomes extremely important. Whilst different infrastructure assets may have different attributes, governing issues are similar in nature. Prediction of deterioration of some infrastructure is complex since they can constitute of a number of discrete elements with a vast range of influencing factors. A major issue currently faced by local government agencies in Australia is the inability to predict maintenance and replacement expenditure with a reasonable accuracy, which creates situations where emergency repairs would use the funds kept for routine maintenance, which then creates a vicious circle of deterioration.
\end{abstract}

The paper presents an innovative approach based on Markov chain for deterioration modeling of infrastructure assets owned by local councils in Australia. Application of the method for council owned building assets is presented using some early data.

\section{INTRODUCTION}

$\mathrm{M}$ anagement and sustainability of built infrastructure is an extremely important issue being addressed by many research organizations in the world. The research work funded by European communities lead the world in these areas as reported by Flourentzou et al (2000), which are still continuing. There are several approaches reported in recent literature to address the issue. These can be summarized as:

1. Approximate methods where condition of different elements were rated $\mathrm{A}, \mathrm{B}, \mathrm{C}$ and $\mathrm{D}$ or $1,2,3,4,5$ through condition inspections. Deterministic life cycle analysis is conducted assuming the time period of progression of deterioration to be fixed in one state (Hovde, 1998).
2. Same as above with modifications for different exposure conditions and usage through fixed factors calibrated with data (ISO factorial approach Bamforth, 2004, Tepley 1999).

3. Reliability based methods using the discrete Markov chain for deterioration modelling.

4. Reliability based methods using continuous Markov process (Maheswaran et al , 2005).

5. Predicting life cycle of assets considering an integration of three drivers such as Market drivers, physical deterioration and functional obsolescence.

Out of the above, the most common approach used by the industry is a deterministic method based on condition data and fixed deterioration curves. However, these approximate methods lack the ability to account for uncertainties, which is essential to manage risk of maintaining assets to provide the required level of service delivery. Preliminary research at RMIT (Setunge and Kumar, 2005) have indicated that to consider majority of the issues affecting management decision making for effective service delivery of councils a reliability-based approach incorporating some attributes of the ISO factorial approach and consideration of other drivers such as market and functional issues (Allehaux and Tessier, 2002) is essential. Use of Markov chain for deterioration modeling and decision-making is being explored at RMIT University in Australia to address this need.

\section{PREVIOUS WORK}

Previous work on application of Markov process for deterioration modeling of structures have covered deterioration prediction of bridges due to chloride induced corrosion (Maheswaran et al, 2005), concrete structures (Lifecon, 2003) and separate elements of buildings 
(ISO1586, 2000). In no reported work, the application of Markov process has been attempted on a complex infrastructure systems comprising of a number of elements. There have been some issues raised about the application of Markov process for predicting deterioration modeling. The Markov curve has a shape which indicates flattening of the curve toward the end of the period whereas in real structures, opposite is observed. This is normally handled by predicting the last stage using a separate probability distribution (Lifecon, 2003)

\section{PROPOSED METHODOLOGY}

\section{A. Conceptual framework}

In deterioration modeling the attributes of a model randomly change over time. A Markov chain is a probability model, which has a finite-state, for describing a certain type of stochastic process that moves in a sequence of phases through discrete points in time according to fixed probabilities. The process is stochastic because it changes over time in an uncertain manner. In this chain the future states are dependent only on the present state and independent from the any state before the present states. Markov chain consists of transition matrix and initial distribution. Transition matrix consist of a set of finite set of states $S(1,1,3 \ldots n)$ and a propriety $\mathrm{pi} j$ to pass from state $i$ to state $\mathrm{j}$ in one time step $t$. Time can be treated as either discrete (called Discrete-Time Markov Chain) or continuous (called Continuous-Time Markov Chain). In Markov chain the states are continuous and similarly the time could be either discrete (called Discrete-Time Markov Process) or continuous (called Continuous-Time Markov Process).

For any building element a condition rating scheme constitutes of four ratings $A, B, C$ and $D$ where $A$ represents new or nearly new element and do not required any maintenance action. D represents a condition which indicates that the element has to be replaced. For modeling purpose these ratings could be consider as discrete states.

\begin{tabular}{|lll|}
\hline A Excellent & $\begin{array}{l}\text { The element is as new and can be } \\
\text { expected to perform adequately to its } \\
\text { full normal life } \\
\text { The element is sound, operationally } \\
\text { safe, and exhibits only minor } \\
\text { deterioration }\end{array}$ \\
C S Unsatisfactory & $\begin{array}{l}\text { The element is operational but major } \\
\text { repair or replacement will be needed } \\
\text { soon. } \\
\text { The element runs a serious risk of } \\
\text { imminent breakdown }\end{array}$ \\
& Failing &
\end{tabular}

Although the deterioration processes evolve over continuous time, for simplicity discrete time steps could represent these processes (such as the time of the building inspection). Hence in this paper Discrete Time Markov Chain will be considered as a model for predicting the life cycle for buil ding element.

\section{B. Discrete Time Markov Chain}

Discrete Time Markov Chain is a finite-state stochastic process in which the defining random variables are observed at discrete points in time. This chain satisfies Markov property which mean that given that the present state is known, the future probabilistic behavior of the process depends only on the present state regardless of the past. If an element is in state "i", there is a fixed probability, Pij of it going into state $\mathrm{j}$ after the next time step. Pij is called a "transition probability". The matrix P whose ijth entry is Pij is called the transition matrix. Transition matrix consist of a set of finite set of state $S(1,1,3 \ldots n)$ and a propriety $\mathrm{pi} j$ to pass from state $i$ to state $j$ in one time step $t$. In Markov chain pi $\mathrm{j}$ should satisfy two conditions

$$
\sum_{j}^{\mathrm{p}_{\mathrm{ij}}} \begin{aligned}
& \geq 0 \\
& \mathrm{p}_{i j} \leq 1
\end{aligned}
$$

This mean if an element is in state $i$, there is a (Pii) probability that this element will stay in state $i$, and (1- Pii) will move to next state $\mathrm{j}$.

Present state at time $t$ is i: $X_{t}=i$

Next state at time $t+1$ is $j: X_{t}+1=j$

Conditional Probability Statement of Markovian Property:

$$
\begin{aligned}
& P_{\mathrm{I}}\left\{\mathrm{X}_{\mathrm{t}}+1=\mathrm{j} \mid \mathrm{X} 0=\mathrm{k} 0, \mathrm{X} 1=\mathrm{k} 1, \ldots, \mathrm{Xt}=\mathrm{i}\right\}=\operatorname{Pr}\{\mathrm{Xt}+1=\mathrm{j} \mid \\
& \left.\mathrm{X}_{\mathrm{t}}=\mathrm{i}\right\}
\end{aligned}
$$

Discrete time means $\mathrm{t} \in \mathrm{T}=\{0,1,2, \ldots\}$

Figures 1 and 2 show a typical transition matrix. The probability of an element being in a given state at a given point in time can then be depicted by the set of curves shown in figure 3

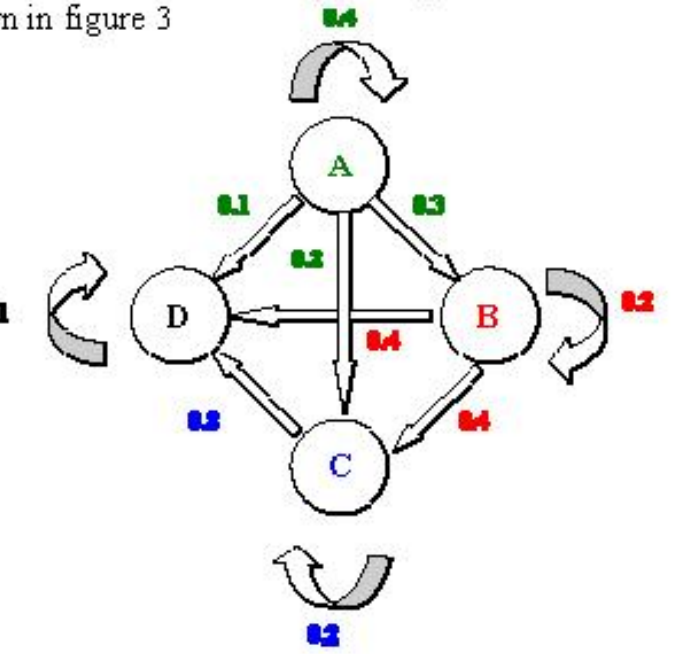


Figure 1: Transition from $\mathrm{A}$ to $\mathrm{D}$

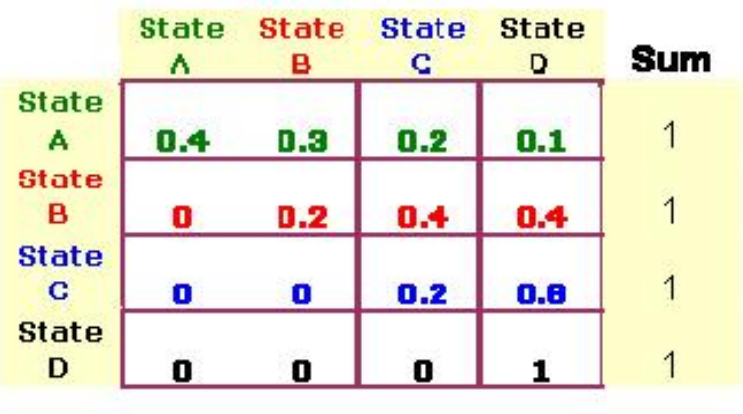

Figure 2: transition Matrix

An initial distribution ' $\mathrm{v}$ ' is a single row matrix representing the number of elements in each state. In Markov chain after one time step the new distribution will be the result of multiplying initial distribution $\mathrm{v}$ by the transition matrix $\mathrm{P}$

Distribution After 1 Step: vP

The distribution one step later, obtained by again multiplying by $\mathrm{P}$, is given by ( $\mathrm{vP}) \mathrm{P}=\mathrm{vP}^{2}$.

Therefore distribution After 2 Steps $=\mathrm{vP}^{2}$

Similarly, the distribution after $n$ steps can be obtained by $\mathrm{vP}^{\mathrm{n}}$

$\mathrm{P}^{2}$ is the two-step transition matrix for the system. Similarly, $\mathrm{P}^{3}$ is the three-step transition matrix, and $\mathrm{P}^{\mathrm{n}}$ is the $\mathrm{n}$-step transition matrix. This means that the ij thentry in $\mathrm{P}^{\mathrm{a}}$ is the probability that the system will pass from state $i$ to state $j$ in n steps.

Probability of an element being in a given state at a given point in time can then be depicted by the set of curves shown in figure 3. Florentzou et al (2000) has used a similar set of curves established empirically from condition data. These curves, once calibrated for a given type of an element exposed to a given exposure condition and a given usage type can be an extremely powerful tool in predicting the reliability based life cycle performance of the element. The reverse cumulative probability corresponding to the conditional probabilities shown in figure 3 can be plotted as shown in figure 4. At a given point in time, the figure 4 can be used evaluate the probability of the element being in a given condition at a given point in time. For example, at 20 years, the element would have $50 \%$ probability of having condition $\mathrm{A}$ and $50 \%$ probability of having condition $\mathrm{B}$.

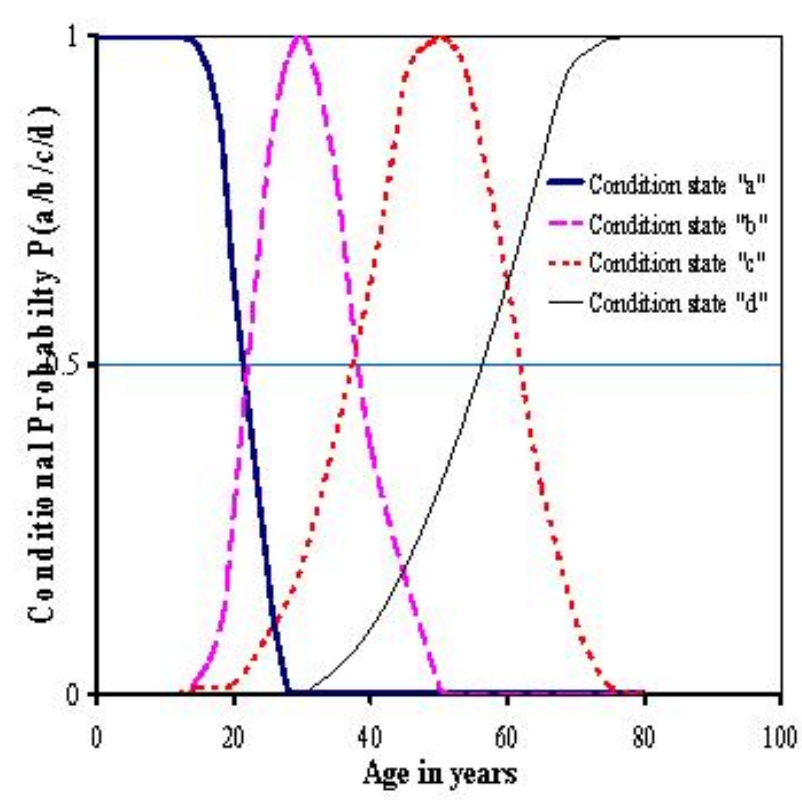

Figure 3: Conditional probabilities

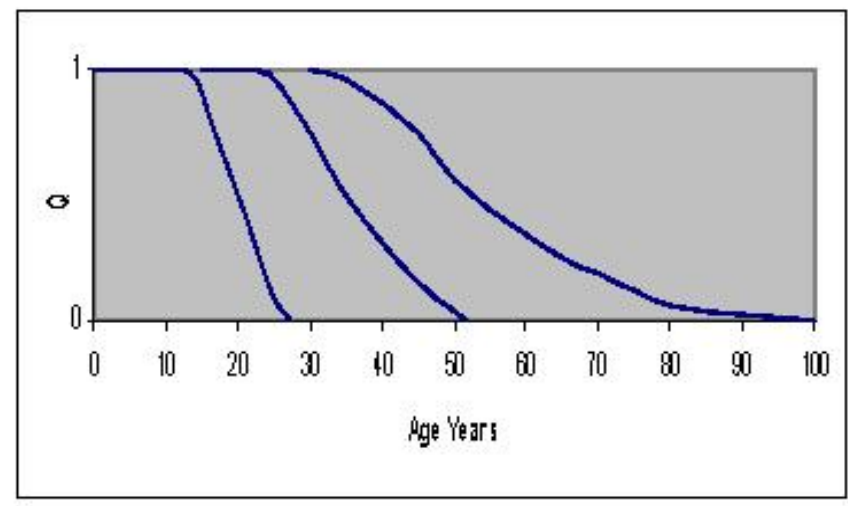

Figure 4: Cumulative Space

\section{Prediction of the future cost}

To predict the future cost for any element there are two kinds of cost:

(i) inspection cost, and

(ii) element replacement cost or element repair cost when the element makes a transition from one state to another.

Inspection cost is represented by the m-dimensional column vector

$$
\mathbf{C}^{s}=\left(c_{1}^{s}, c_{2}^{s}, \ldots, c_{m}^{s}\right)^{\mathrm{T}}
$$

where each component is the cost associated with state i. 
The cost of a transition is embodied in the $\mathrm{m} \times \mathrm{m}$ matrix

$$
\mathbf{C}^{\mathrm{R}}=\left(c_{i j}^{\mathrm{R}}\right)
$$

where each component specifies the cost of going from state $i$ to state $\mathrm{j}$ in a single step.

Expected cost of being in state i, (Jensen and Bard(2003)) is given by:

$$
c_{i}=c_{i}^{\mathrm{S}}+\sum_{j=1}^{m} c_{i j}^{\mathrm{R}} p_{a i j}
$$

Where, $p_{a i j}$ is the probability of maintenance action.

\section{Absorbing states}

An absorbing state is a state from which there is a zero probability of exiting. An absorbing state is a state $\mathrm{j}$ with $\mathrm{pjj}_{\mathrm{j}}=1$. In other words, without any maintenance action, element which reached condition $\mathrm{D}$ will stay in that condition forever. Calculating the expected number of steps to absorption (elements pass from different states to end up in state D) can help to obtain an overall view about the estimated life cycle for that element.

To calculate the absorbing states

Let $0,1, \ldots, k$ be transient states and

$k+1, \ldots, m-1$ be absorbing states.

Let $q i j=$ probability of being absorbed in state $j$

given that we start in transient state $i$.

Then for each $j$ we have the following relationship

$$
q i j=\text { pij }+\sum \text { pirqri }, i=0,1, \ldots, k
$$

For fixed $j$ (absorbing state) we have $k+1$ linear equations in $k+1$ unknowns, $q r j, i=0,1, \ldots, k$.

\section{E. Long term behaviour of the Markov Chain}

If there are recurrent actions taken to repair or replace the element in any state it leads to a steady state probability, which help to set a stable maintenance plan and expenditure.

Calculation of steady state probability can be given by,

Let $\pi=(\pi 1, \pi 2, \ldots, \pi m)$ is the $m$-dimensional row vector of steady-state probabilities for the state space $S=$ $\{1, \ldots, m\}$. To find steady-state probabilities, solve linear system:

$$
\boldsymbol{\pi}=\boldsymbol{\pi} \mathbf{P}, \quad \mathrm{S} j=1, m \pi j=1, \pi j \geq 0, j=1, \ldots, m
$$

\section{F. Application}

A major challenge in application of the proposed concepts is the quality and quantity of the data needed. A probability distribution is needed for all major data categories for elements of an infrastructure system. With the support of the Brimbank City Council in Victoria, data are currently being collected for this purpose.

\section{Demonstration of the proposed method for key building elements}

Process is demonstrated with a division of a building into six key elements:

1. Structure

2. External Finishes

3. Internal Finishes

4. Fixtures and Fittings

5. Mechanical and electrical services

Figure 5 shows probability curves for the building external finishes with time. The time step considered is 1 year with external finishes reaching the condition ' $\mathrm{D}$ " in 5 years. Transition matrix derived for the given probability curves are shown in figure 6.

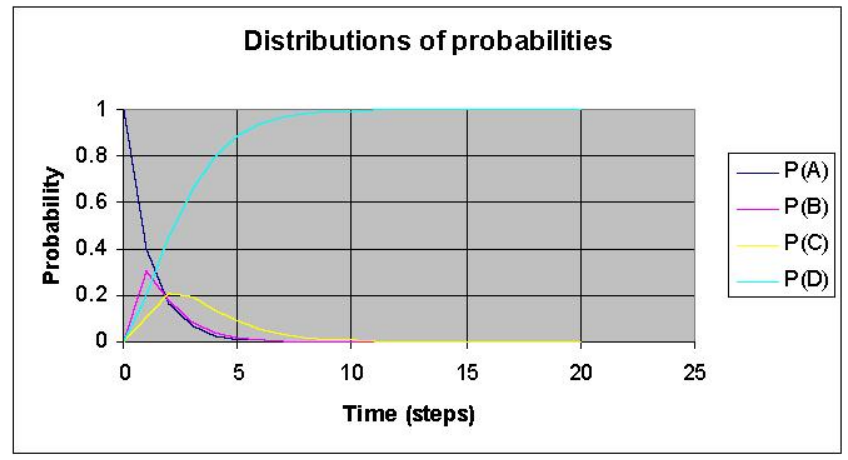

Figure 5: Cumulative Space

\begin{tabular}{c|r|r|r|r|}
\multicolumn{1}{c}{} & \multicolumn{1}{c}{ State 0 } & \multicolumn{1}{c}{ State 1 } & \multicolumn{1}{c}{ State 2 } & \multicolumn{1}{c}{ State 3 } \\
\cline { 2 - 5 } State 0 & 0.4 & 0.3 & 0.1 & 0.2 \\
\cline { 2 - 5 } State 1 & 0 & 0.2 & 0.4 & 0.4 \\
\cline { 2 - 5 } State 2 & 0 & 0 & 0.5 & 0.5 \\
\cline { 2 - 5 } State 3 & 0 & 0 & 0 & 1 \\
Sum & 0.4 & 0.5 & 1 & 2.1
\end{tabular}

Figure 6: Corresponding transition matrix

\section{Forecasting of the deterioration of the building}

Once the transition matrix is developed for a given element type, the cost of maintenance can be calculated as a function of the deterioration curves. Figure 7 shows the forecast expenditure without a maintenance plan for $90 \%$ confidence. 


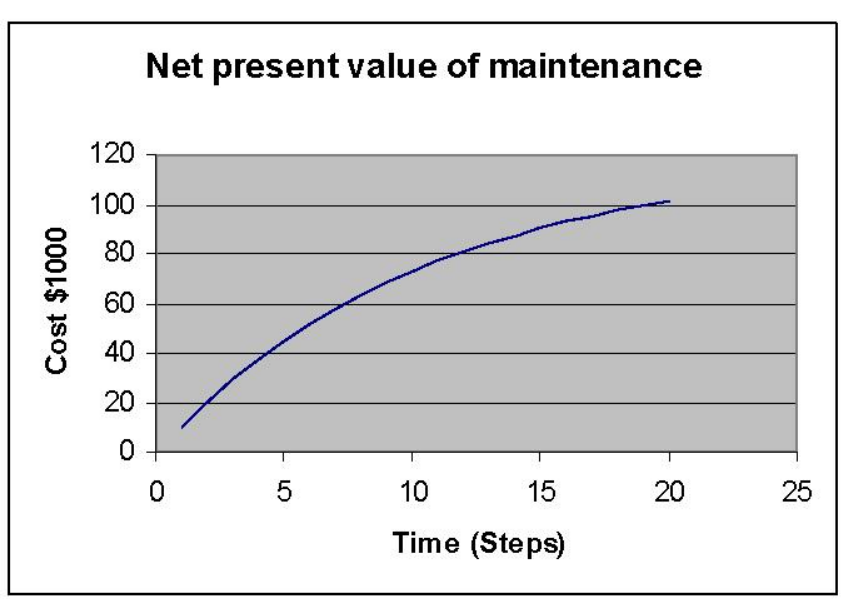

Figure 7: Forecast expenditure

\section{Conclusions}

The paper presented the concept of using Markov chain for deterioration modeling of buildings. The data collection regime for validation of the proposed method is given. Using a higher level division of building into elements and some approximate data based on expert opinion, the method of application of the proposed method is demonstrated.

The cost of maintenance activities can be estimated for a given level of confidence as opposed to a deterministic measure, which allows the infrastructure asset owner to select a given level of risk in managing critical infrastructure.

\section{ACKNOWLEDGMENT}

Support of the Brimbank City Council in Melbourne, Victoria is gratefully acknowledged in provision of expertise and data for the project.

\section{REFERENCES}

1. Allehaux, D. and Tessier, P. (2002), "Evaluation of the functional obosolenscene of building services in European office buildings" Joumal of Energy and buildings, 34, pp.127-133

2. Bamforth, P., (2004) "Probabalistic approach for predictiong life cycle costs and performance of buildings and civil infrastructures". Proceedings of the $2^{\text {nd }}$ International Symposium on Integrated Life-time Engineering of Buildings and Infrastructures, Kuopio, Finland, pp.553-558.

3. Box, G.E.P. and Tiao, G.C. (1975). Intervention Analysis with Applications to Economic and Enviromental Problems. Journal of the American Statistical Association 70, no. 349, pp. 70-79.

4. Caccavelli D., Genre, J.-L. (2000), "Diagnosis of the degradation state of the building and cost evaluation of induced refurbishment works" Journal of Energy and buildings, 31, pp.159-165

5. Flourentzou, F., Brandt, E., Wetzel, C. (2000), "MEDIC-a method for predicting residual service life and refurbishment investment budgets" Journal of Energy and buildings, 31, pp.167-170

6. Hovde, P.J., (1998). "Evaluation of the factor method to estimate the service life of building components", Materials and technologies for sustainable construction, CIB world building congress, 1998, Gavle, Sweden, 7-12 June.

7. Hovde, P.J., and Moser, K., (2004). "Performance based methods for service life prediction" State of the art reports, CIB Report: Publication 294, ISBN: 90-6363-040-9, CIB, NTNU and EMPA, 2004.

8. ISO 15686 Part 1, (2000). "Building and constructed assets - Service Life Planning - Part 1: General principles". International Organisation for Standardisation, Geneve, Switzerland.

9. ISO 15686 Part 2, (2001). "Building and construction assets - Service Life Planning - Part 2: Service Life prediction procedures". International Organisation for Standardisation, Geneve, Switzerland.

10. Jensen. Paul A. and Bard Jonathan F(2003), "Operations Research Models and Methods", John Wiley and Sons.availble on line http://www.me.utexas.edu/ jensen/ORMM/index.h $\underline{\mathrm{tml}}$

11. Kemeny, J.G. and J.L. Snell (1960). Finite Markov Chain. D. Van Nostrand Company, Inc., Princeton, New Jersey

12. Life Cycle Management System, LIFECON, Report 05.04.2004

13. Life Cycle Analysis, A life cycle cost and risk analysis tool for rehabilitation of bridge structures. Commercialisation is in progress through CRC for Construction Innovation. (demo version available at www.integrate-aus.com.au)

14. Lounis, Z., Lacasse, M.A., Vanier, D.J., and Kyle, B.R., (1998). "Towards standardisation of service life prediction of roofing membranes". Roofing research and standards development: $4^{\text {th }}$ volume, ASTM STP 1349, PA, USA.

15. Madanat, S.(1993) "Optimal Infrastructure Management Decisions Under Uncertainty,"Transportation Research Part C, Vol. 1C, No. 1

16. Maheswaran, T., Sanjayan, J.G., and Taplin, G., (2005). "Deterioration modeling and prioritizing of reinforced concrete bridges for maintenance", Australian Journal of Civil Engineering, Vol 2, No 1 , pp 1-12. 
17. Makridakis, S., Wheelwright, S. and McGee, V. (1983). Forecasting: Methods and Applications. Second Edition. John Wiley \& Sons, New York.

18. Nezamian, A., Setunge, S. and Fenwick J. M. (2004) "Reliability Based Optimal Solution for Rehabilitation of Existing Bridge Structures" Proceedings of the Clients Driving Innovation International Conference, October 2004, Surfers Paradise, Queensland, Australia, pp. 10

19. RILEM (1989). "Systematic methodology for service life prediction of building materials and components". RILEM recommendation, Materials and Structures, vol.22, pp. 385-392.

20. Ross S (2000). Introduction to Probability Models, 7th ed Academic Press: New York.

21. Sennott, L.I. (1999) Stochastic Dynamic Programming and the Control of Queueing Systems. John Wiley and Sons. New York.

22. Theodore, J.G., (1994). "THE DELPHI METHOD", AC/UNU Millennium Project on Futures Research methodology.

23. Teply, B.,(1999). "Service life prediction of structures - Factor method", Stavebni Obzor (Structural Horizon), Vol 8. pp. 137-139 (In Czech).

24. Weisstein. E.W., "Markov process",A

WolframWebresource

http://mathworld.wolfram.com.au/MarkovProcess. $\underline{\mathrm{html}}$ 